\title{
The Applications of Psychological Effects in Game Design and Suggestions for Parents and Teenagers
}

\author{
Xuan $\mathrm{Cao}^{1,1 \mathrm{st}^{*}}$, Yi Huang ${ }^{2,1 \mathrm{st}}$ \\ ${ }^{1}$ Lawrence Woodmere Academy, New York, United States, 11598 \\ ${ }^{2}$ Beijing Royal School, Beijing, China, 102209 \\ *Corresponding author. Email: xcao@lawrencewoodmere.org
}

\begin{abstract}
According to the 2020 China Gaming Industry Report released by China Audio-Video and Digital Publishing Association, the annual revenue of China's gaming industry increased to 278.7 billion yuan (about 43.2 billion U.S. dollars) in 2020, up $20.71 \%$ from the previous year [1]. The rapid growth of revenue in the game industry comes from the general increase of players' spending on games. The rise of spending is inseparable from the well-planned guidance of businesses. From the perspective of behavioral economics and psychology, this paper analyzes how businesses apply psychological effects to game design through theory and application. The psychological effects used by game designers include the foot-in-the-door effect, ratchet effect, scarcity effect, and goal gradient effect. The purpose of this paper is to explore how game designers use multiple psychological effects to induce players to be willing to spend for the game. The results show that the psychological effect is an excellent reference in game design, which makes it difficult for players to escape from the consumption trap well-planned by game designers. Players will eventually become addicted to the game and spend more, especially minors with immature consumption concept.
\end{abstract}

Keywords: game consumption, psychological effect, behavioral economics, game addiction, teenagers

\section{INTRODUCTION}

In the field of game addiction, computer-side games (such as most games on the steam game platform) have been investigated and analyzed by more people. However, mobile games are rarely noticed. Because mobile games have fewer players than computer games, and the game screen and quality can be better presented on the computer. As a result, this report on mobile games was written. The themes of this analysis are described in terms of how game designers use multiple psychological effects to make players consume for games, how to advise parents to prevent underage game addiction, and how to stop underage people from becoming addicted to games. The juvenile game protection mechanism introduced by Tencent Games, one of China's domestic game giants, is used to reflect the dangers of teenage game addiction. The specific problem of the article is to explore the psychological process of players who are unwilling to consume from the beginning when playing games, and then analyze the mental process of large-scale consumption. This paper first analyzes the high annual profits of some Tencent games to reflect the consumer behavior of players willing to spend money for the game, and then analyzes the psychological effects of players to understand how these effects are applied by the merchants to the game consumers. Finally, we advise young consumers to maintain a rational attitude towards games. China's high game consumption and the negative impacts of game addiction on young people have attracted the attention of the government. Therefore, it is urgent to solve the problem of game addiction. Of course, not all games are bad, but teenagers need to be guided correctly to avoid self-degeneration.

\section{PSYCHOLOGICAL EFFECTS APPLIED IN GAME DESIGN}

In 2020, PUBG Mobile, a mobile game published by Tencent Games, grossed more than 2.6 billion U.S. dollars and was the top-grossing title worldwide. Second-ranked Honor of Glory generated 2.5 billion U.S. dollars in player spending, up $42.8 \%$ from the year prior [2]. Behind the sky-high profits in the game industry is the tailored consumption trap woven for consumers, by game designers that use multiple 
psychological effects. The following paragraphs focus on exploring what psychological effects are used and how they are applied in the game by the game designers.

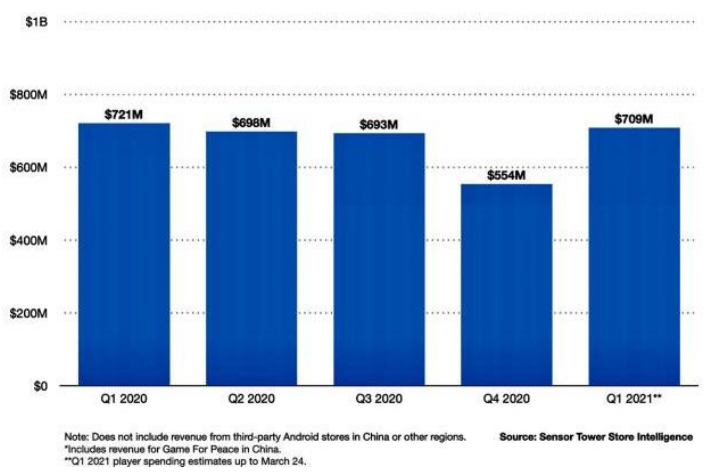

Figure 1: PUBG Mobile Global Player Spending by Quarter [3]

\subsection{Foot in the Door Effect}

First of all, for those players who do not plan to consume, their first step of consuming is ascribed by the "foot in the door effect", a persuasive technique that increases compliance to a request. It assumes agreeing to a small request increases the likelihood of agreeing to a second, larger request. You first make a small request and once the person agrees to this, they find it more difficult to refuse a bigger one. Players may not spend 50 yuan for a virtual game accessory at first, but game designers usually launch a first-charge coupon with $80 \%$ off for novices. When 10 yuan buys a 50-yuan-commodity, whether the commodity itself is worth it or not, the price difference will make consumers feel cheap, so most players are willing to pay. The huge discounts provided by game designers make players feel that they have found a bargain. In fact, it is the key for game designers to convert players into consumers and turn on the "addictive mode". The first few yuan may not mean to be addictive, but the second trap set by the designer follows.

\subsection{Ratchet Effect}

The Ratchet Effect is a mechanical analogy in economics that refers to a process that moves easily in one direction but not the other. It means that when people's consumption habits have formed, it turns out hard to be reversible. Consumption decisions are few to be rational plans, it normally depends on consumption habits. After several preferential recharge that is intentionally offered by the game merchants, players' consumption habits are quietly changed by the merchants. The game designers will then launch advanced but expensive props. At this time, players already have the habit to consume their loved game props, so it will be hard for them to resist the temptation but choose to continue the consumption. With the gradual improvement of players' consumption level, their consumption habits are like gears. The gears have got used to running in a certain direction. It is difficult to turn back. That is, after using advanced props, players will feel bored with ordinary props. The consumption habits of players depend on the peak of past consumption level, and each purchase will increase the threshold. As the threshold rises, the consumption level will go up and players are more willing to pay. The general consumption level of game players has raised steadily year by year [1]. Painstakingly, the game designers take advantage of the ratchet effect to cultivate players' consumption habits, so they cannot stop here. The huge benefits brought by the scarcity effect should also not be ignored.

\subsection{Scarcity Effect}

To induce players to recharge, the designer occasionally launches discount promotions or limited game props. Consumers place a higher value on goods that are scarce than abundant. The feigned scarcity causes a surge in the demand for the commodity. The thought that people want something they cannot have driven them to desire the object even more. Research has shown that scarcity makes consumers feel more unique, special, and valuable if they possess a limited products [4]. Restricted products and time-limited sales will stimulate people's desire to buy, which will lead to irrational consumption of consumers. The luxury brand Hermès represents a typical case. The brand never reports the number of Birkin handbags they sell each year. Besides, the exclusive information concerning the handbags also makes them even harder to purchase. Hermès only offers its most loyal and highest-spending clients the opportunity to get into a waiting list for the new series, even when the waiting list is usually several years long. That is why the price of a Birkin soars once it enters the second-hand market [5]. Similarly, the number of epic props launched by game designers is usually limited. Assuming the designers set the probability as only $0.03 \%$ of players in the whole game server can own a certain prop, this prop will then become valuable and makes more players eager to own it. Having scarce goods satisfies the vanity of consumers because such goods are endowed with extra value, making them expensive but attractive. Other than the quantity limit, the time-limited sales deliberately designed by game merchants means to stimulate people's anxiety. To alleviate anxiety, players are easier to make purchase decisions. This marketing psychology is normally seen in sales days. For those goods that are unnecessary to buy, merchants would launch a flash sale that delivers a message of "miss is a loss" to consumers, which results in irrational consumption. In general, game designers will release festival limited products in holidays, such as Christmas. Many players are worried that these limited products will not be available in the 
shop later, so anxiety and hesitation eventually lead them to consume.

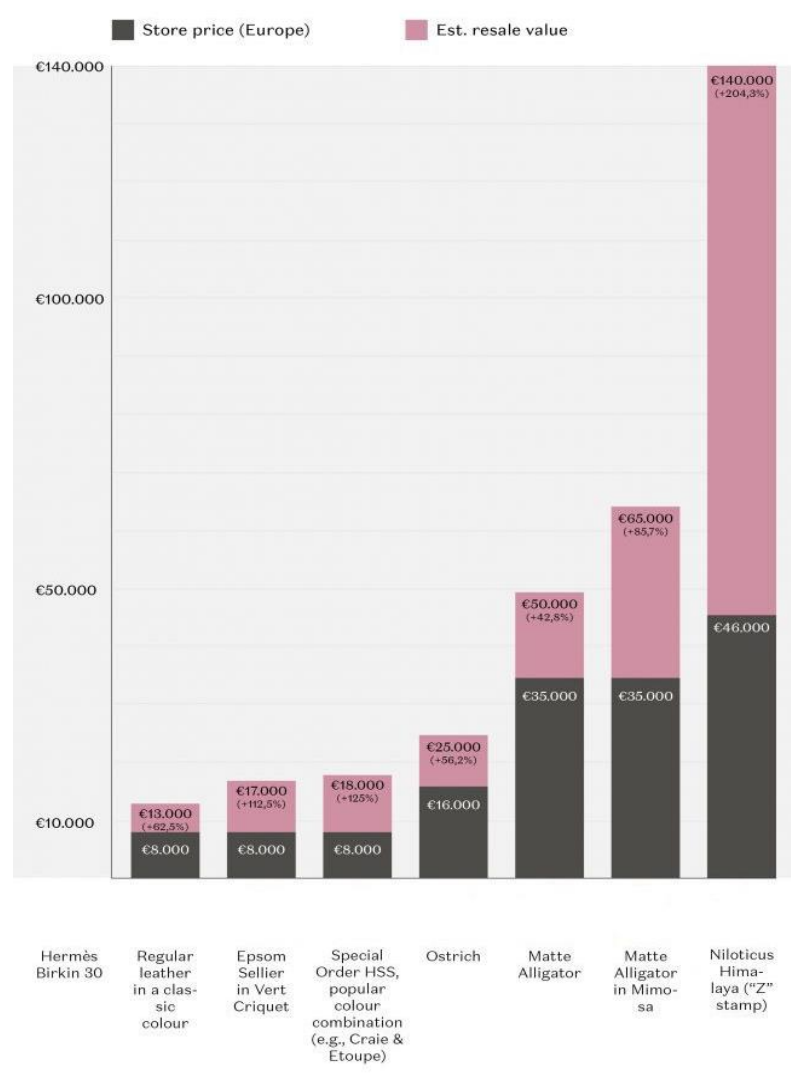

Figure 2: Prices and Resale Value of a Birkin 30 in Like-New Condition [6]

\subsection{Goal Gradient Effect}

The goal gradient effect is widely shown in every part of a game, such as game level promotion or task progress. The effect states that as people get closer to a reward, they will speed up their behavior to get their goal faster. In games, the progress is usually shown as a percentage. The visualization of progress imperceptibly sets goals for players. Rewards are shown. As the progress percentage increases, the players' desire to complete the goal becomes stronger. Consumption accumulation is also shown in the progress bar. In the progress bar, normally there will be a small gift for every consumption of $100 \mathrm{RMB}$, and an epic prop for the total consumption of 500RMB. As the reward gets closer, players are more willing to consume. Most of the games have a lucky draw. To engage more players in the lucky draw, the system normally has a minimum guarantee. Even if the player has a probability to draw the target reward soon, the designer still promises that the target reward will be given after the player draws certain times, such as 200. The existence of the minimum guarantee is to set a goal for players. A player might leave after drawing 20 times without getting a target reward. However, the minimum guarantee allows the target progress to be visualized. The previous 20 draws are visible in the progress bar, which makes the player seem to get closer to the target, therefore it is more likely for the player to pay for the whole 200 drawing times to get the target reward.

\section{SUGGESTIONS}

\subsection{Gaming suggestions for adolescents}

Game addiction is currently one of the most discussed psychosocial aspects associated with playing computer and video games. A study in 2017 reported that $67.2 \%$ of the people in the age of $10 \sim 65$ were playing internet games, and the ratio of game users was highest in teenagers at $91.1 \%$ [7]. It has also been noted that various problems in academic achievement, family relationships, social relationships, physical and mental health problems could occur as the result of game addiction when games were excessively played. There are extensive examples of families breaking apart just because of kids' game addiction. Game addiction would also destroy adolescents' whole life because when people spend days and nights on games, it's impossible for them to have the energy to concentrate on class. Therefore, the momentary pleasure of playing games will only make people fall into the abyss. Playing video games is extremely harmful to the eyes. From a long-term perspective, many professions do not allow people with myopia to participate, so it is extremely not worthwhile to ruin eyes for the sake of the game. Also, by playing games online, whether mobile games or computer games, people's mental health would be affected. According to Sung, Y., Nam, T. H., \& Hwang, M. H. [8], at the level of correlational analyses, both attachment anxiety and attachment avoidance were significantly associated with symptoms of Internet gaming addiction, suggesting insecurely attached students are likely to engage in more problematic gaming [9]. However, there are some simple and easy ways to get rid of game addictions. First, get away from the people who try to persuade you to play video games with them, because the chain reaction would only make everything worse. When people have the ability and courage to reject others, they truly grow up. Also, the addiction to the game can be transferred to other places. For example, cultivating a new hobby will be a good solution to game addiction. Because the appeal of games is not so severe, and the newly raised hobbies are healthy and active, the meaning of life may also be discovered.

\subsection{The ways that parents can adopt to avoid kids'game addiction}

Parents play an important role in reducing game addiction. Parent-child closeness, a warm family environment communication, or conversations between 
parent and child and perceived family harmony are all associated with lower levels of game addiction [10-12]. Nationally, the Chinese government has already paid attention to the problem of game addiction, since many online games represented by the game of King of Glory, have made many children who are going to junior high school, high school, and even elementary school now addicted to the game. China's current national policy stipulates this: if minors have not passed the identity verification, they can only play games on Friday, Saturday, and Sunday evenings from 8 to $9 \mathrm{pm}$. These policies include China's largest game company, Tencent Games, and NetEase games, which are also very popular today, as well as some other smaller games. However, there are still many minors who use the elderly at home to "coax" the game system, because the elderly love their children and do not understand the purpose of face recognition. These "smart" children make the system think that adults are playing. Games, and then they can play games unscrupulously. The point the author wants to emphasize here is that parents need to pay attention to their children's games at any time. For example, Tencent Games has a "Growth Guardian Center". In this official account, parents can see how long their children have played the games and how much money has been charged for games at any time and anywhere. It is worth mentioning that the accounts suspected to be minors will show face recognition at any time to ensure the safety of the games of minors. If the children at home are already addicted to games, there are several ways to solve this situation. First, giving children appropriate rewards through academic achievement will make them feel the fun of earning the length of the game by themselves, so children will have the motivation to learn and play games in an open manner, instead of hiding their parents from playing games as before. On the contrary, if parents use the method of beating and scolding to solve this problem, the children will have a rebellious mentality, and teenagers who are in the rebellious period are prone to make mistakes, and at this time, they should not be treated roughly. What's more, the formulation of rules is also very important. For example, parents can specify the time for their kids to play games, which is good for children and saves parents' energy.

\section{CONCLUSION}

Based on behavioral economics and psychology perspectives, the above theoretical and applied analysis of the use of multiple psychological effects of game design confirms that game designers have huge impacts on players' consumption decisions. Especially teenagers are more likely to be induced to be addicted to playing games and have excessive consumption. Behind the great rise of game industry revenue, there are many hidden drawbacks. China currently has introduced anti-addiction policies and regulations for teenage game consumption and addiction. However, the measures for this area are not yet perfect. Foot in the Door Effect, Ratchet Effect, Scarcity Effect, and Goal Gradient Effect have been confirmed that they are applied in game designs to attract players to consume and purchase. Furthermore, different suggestions are made from the perspective of teenagers and parents. First of all, from the perspective of adolescents, game addiction will not only have a great impact on vision, but it will also affect learning concentration and performance, and parents will also be disappointed in their children. For parents, there are many ways to avoid children's addiction to games. First, Tencent Games, as one of the Chinese gaming giants, has launched a game anti-addiction system. This system has human face recognition to help parents prevent children from playing games uncontrollably. When children perform well, appropriate game rewards are necessary. The important point is that violence is infeasible. In future papers, questionnaires will be designed to obtain data and get a more in-depth analysis. The future indication is that more people can pay attention to the drawbacks brought by the game industry, instead of blindly seeing the huge profits of the game industry.

\section{AUTHORS' CONTRIBUTIONS}

This paper is completed by Xuan Cao and Yi Huang together.

\section{ACKNOWLEDGEMENTS}

First, we would like to thank our two professors, Louis Putterman and Nathan Novemsky, for their teaching and inspiration on the paper. Without their guidance on our economics study, the topic would not have come out so smoothly. Then, we are grateful to our paper advisor-Ms. Wang, for her great support and patient guidance in helping us with the paper outline and structure. Finally, we appreciate our hard work, for all the time and effort we two have paid, to build this total 2800 -words paper. Thanks for all the cooperation and mutual help.

\section{REFERENCES}

[1] Yi Jun Zhang, 2020 China Gaming Industry Report. Dec. 18, 2020 http://www.cgigc.com.cn/gamedata/22132.html

[2] Chapple Craig, PUBG Mobile Tops List of Billion-Dollar Mobile Games in 2020. Dec. 15, 2020.

https://sensortower.com/blog/pubg-mobile-tops-bill ion-dollar-mobile-games-2020

[3] Craig Chapple, PUBG Mobile Grosses \$5 Billion After Generating an Average of \$7.4 Million Per Day in 2020 , Mar 25, 2021. 
https://sensortower.com/blog/pubg-mobile-five-bill ion-revenue

[4] Aggarwal, P, Jun, S. Y, \& Huh, J. H, Scarcity Messages [J] Journal of Advertising, 2011, pp.1930.

[5] Lewis, T L, \& Haas, B, Managing an iconic old luxury brand in a new luxury economy: Hermès handbags in the US market. Global Fashion Brands: Style, Luxury \& History[M] Intellect, 2014 , pp.167-178.

[6] Suzannah Wilkinson, Why is the Hermès Birkin So Expensive, 2021. https://saclab.com/why-is-the-hermes-birkin-so-exp ensive/

[7] Lemmens, J. S., Valkenburg, P. M., \& Peter, J. (2009). Development and validation of a game addiction scale for adolescents. Media psychology, 12(1), 77-95.

[8] Do, E. Y., \& Hong, Y. R. (2020). Factors Influencing Internet Game Addiction in Middle School Students. Medico Legal Update, 20(1), 2167-2172.

[9] Sung, Y., Nam, T. H., \& Hwang, M. H. (2020). Attachment style, stressful events, and Internet gaming addiction in Korean university students. Personality and Individual Differences, 154, 109724.

[10] Choo H, Sim T, Liau AKF, Gentile DA, Khoo A. 2015. Parental influences on pathological symptoms of video-gaming among children and adolescents: as prospective study. J Child Fam Stud. 24:1429-1441.

[11] Liau AK, Choo H, Li D, Gentile DA, Sim T, Khoo A. 2015. Pathological video-gaming among youth: a prospective study examining dynamic protective factors. Addict Res Theory. 23:301-308.

[12] Kim M. 2012. Influence of adolescents' psychological variables and attachment with parents upon internet game addicts and cellular phone addicts. Korean J Hum Dev. 19:1-22. 